\title{
Growth and survival of recently settled snow crab Chionoecetes opilio in relation to intra- and intercohort competition and cannibalism: a laboratory study
}

\author{
B. Sainte-Marie*, M. Lafrance \\ Direction des invertébrés et de la biologie expérimentale, Institut Maurice-Lamontagne, Pêches et Océans Canada, \\ 850 route de la Mer, CP 1000, Mont-Joli, Québec G5H 3Z4, Canada
}

\begin{abstract}
A laboratory experiment was conducted on snow crab Chionoecetes opilio to test the hypothesis that abundance of recently settled crabs is more likely to be regulated by cannibalism between than within cohorts. Growth and mortality of postlarval Instar I crabs (3 mm carapace width, forming the junior cohort) at different densities (7, 14, 28 or 56 by tray), or at constant density (56 by tray) but in the presence of 1, 3, 6, 9, 12 or 24 postlarval Instar V crabs (14 mm carapace width, forming the senior cohort), was recorded over $104 \mathrm{~d}$. With the junior cohort alone, mean proportional survival of crabs was high (64 to $81 \%$ ), independent of density, and similar to that of individually reared crabs $(68 \%)$. However, the first and second molts occurred increasingly late as density increased, possibly reflecting growing levels of agonism and competition. Molting crabs were not particularly vulnerable to cannibalism. In treatments mixing the junior and senior cohorts, mean proportional survival of junior crabs decreased from $31 \%$ in the presence of 1 Instar $V$ to $0 \%$ in the presence of 9 or more Instar $\mathrm{V}$ and the prevalence and intensity of limb loss for survivors increased with density of the senior cohort. Cannibalism was the additional or sole source of mortality for junior crabs in treatments with Instar V crabs and it occurred swiftly in the first $5 \mathrm{~d}$ of the experiment. Moreover, the presence of any number of larger conspecifics resulted in a severe delay in molting of junior crabs compared to control (no Instar V crabs). Therefore, intercohort predation is more important than intracohort predation or competition as a process effecting year class strength and condition during the early benthic stages of snow crab.
\end{abstract}

KEY WORDS: Snow crab · Chionoecetes opilio · Intraspecific predation · Cannibalism • Competition · Density dependence $\cdot$ Growth $\cdot$ Population dynamics

Resale or republication not permitted without written consent of the publisher

\section{INTRODUCTION}

The megalopae of many species of marine brachyuran crabs settle selectively in certain types of habitat. Environmental cues influencing metamorphosis and settlement include light, salinity, sediment type and physical structures or biota offering shelter (Christy

*Email: sainte-marieb@dfo-mpo.gc.ca
1989, Fernández et al. 1993b, Forward et al. 1994), as well as odors from conspecifics, hosts or predators (Castro 1978, Banks \& Dinnel 2000, Gebauer et al. 2002). Recently settled crabs may be spatially concentrated and several cohorts of juveniles may co-habit if growth and dispersal are slow enough (Orth \& Van Montfrans 1987, McMillan et al. 1995, Comeau et al. 1998). Concentration of juvenile crabs into nursery areas leads to intra- and intercohort competition for space and food (e.g. Iribarne et al. 1994), and in species 
which exhibit cannibalistic behavior, early juveniles may be preyed upon by conspecifics of the same or older cohorts (Fernández et al. 1993a, Moksnes et al. 1997, Luppi et al. 2001).

Cannibalism is thought to be an important factor affecting year class strength and fishery recruitment, through differential survival of successive cohorts, in several species of brachyuran crabs (Botsford \& Hobbs 1995, Hines \& Ruiz 1995, Fernández \& Castilla 2000). Cannibalism, or the risk of cannibalism, can conceivably result in a spectrum of effects on potential prey ranging from reduced growth, caused by stress, lower food intake or sublethal injury, to death. Experimental studies of cannibalism on recently settled brachyuran crabs have typically lasted less than $48 \mathrm{~h}$ and have focused on mortality as the outcome (e.g. Fernández et al. 1993a, Moksnes et al. 1997, Luppi et al. 2001). Thus, very little is known of the sublethal effects of cannibalism on recently settled brachyuran crabs.

The snow crab Chionoecetes opilio is a major invertebrate predator (Tarverdieva 1976, Lovrich \& SainteMarie 1997) and fishery resource (Ivanov \& Sokolov 1997, Comeau et al. 1998, Zheng \& Kruse 2000) on cold shelf or slope areas of the North Pacific and Northwest Atlantic. Recruitment of snow crab to the fishery is unstable interannually and it seemingly occurs as alternating multiyear periods of strong or weak recruitment (Elner \& Beninger 1995, Conan et al. 1996, Sainte-Marie et al. 1996, Zheng \& Kruse 2000). Snow crab is cannibalistic (Yasuda 1967, Dutil et al. 1997) and this behavior has been proposed as a possible mechanism of recruitment periodicity. Lovrich et al. (1995) and Sainte-Marie et al. (1995) posited that nursery grounds gradually become saturated through successive annual settlement events such that survivorship of megalopae and recently settled crabs is more or less compromised by cannibalism until crabs in the last successful cohorts begin to disperse from nurseries, at about age 4 yr. Evidence in support of this hypothesis is still fragmentary. Short-term laboratory experiments with intermolt (hard-shell) snow crabs have shown that there is little or no intracohort predation within groups of first postlarval instar crabs or of similarly sized older juveniles, but that larger crabs readily prey on smaller juveniles (Dutil et al. 1997, Lovrich \& Sainte-Marie 1997). However, neither of these 2 experimental studies tested the possibility that intracohort predation is a significant source of mortality only during the critical period of molting (see Yasuda 1967). The size structure of conspecific prey in the stomachs of wild snow crabs also suggested that early juveniles are cannibalized only by individuals of older cohorts (Lovrich \& SainteMarie 1997). However, as pointed out by Fernández (1999), stomach content analysis may be ineffective for detecting intracohort predation if only postmolt (soft-shell) prey are taken or if they are only partly ingested.

We conducted a controlled laboratory experiment to assess the potential roles of intra- and inter-cohort cannibalism on early juveniles as a population regulatory process in snow crab, and to evaluate the timing and sublethal effects of cannibalism on recently settled individuals. This approach is essential for investigation of post-settlement processes in snow crab because the center of depth distribution for early juveniles lies out of the reach of divers (Lovrich et al. 1995, Comeau et al. 1998). Our experiment differs from previous efforts in having tested a large but realistic range of prey and potential predator densities, over a period of time spanning more than 1 molt cycle, and in a laboratory setting offering partial refuge from predation. Three hypotheses were tested: (1) intracohort cannibalism is not an important source of mortality and its magnitude is density independent; (2) intercohort cannibalism can be a major source of mortality and its magnitude is dependent on predator density; and (3) recently settled crabs are more vulnerable to cannibalism at molting than at other times of their molt cycle.

\section{MATERIALS AND METHODS}

Experimental procedure. Snow crab females brooding ripe embryos and juveniles belonging to postlarval Instar V were collected by beam trawl in the northwest Gulf of St. Lawrence (eastern Canada). Snow crabs can easily be attributed to a postlarval instar on the basis of body size, owing to discrete modes in juvenile size frequency distributions (see Fig. 1 in Lovrich et al. 1995). Postlarval Instar I snow crabs were obtained by hatching and rearing larvae in the Maurice Lamontagne Institute facilities. Larvae from 24 females were reared in 40 or 601 kriesel tanks following methods in Lovrich \& Ouellet (1994), with the exception that a suspension of $3 \mathrm{ml}$ of puréed shrimp Pandalus borealis was added daily to the $40 \mathrm{l}$ tanks, and $5 \mathrm{ml}$ to the $60 \mathrm{l}$ tanks, along with the Artemia nauplii. Field collected Instar V snow crabs were used as potential predators and their size ranged from 12 to $16 \mathrm{~mm}$ in carapace width (CW), with a mean and SD of $14.17 \pm 0.65 \mathrm{~mm}$. Crabs used in the experiment were selected to be intact (no missing limbs, no visible lesions), after which they were allocated randomly among treatments. No distinction of gender was made for Instar I, as this is impossible without invasive microscopic examination. The overall ratio of male to female Instar V crabs in treatments was 0.83:1.

Treatments were housed in trays with a $31.5 \times$ $39.0 \mathrm{~cm}\left(=0.123 \mathrm{~m}^{2}\right)$ bottom area and a water depth of $6.5 \mathrm{~cm}$. The fixed bottom and the removable cover of 
the tray were fitted with $1 \mathrm{~mm}$ Nitex mesh. A recess in the tray's side wall at the junction with the bottom mesh allowed Instar I crabs to hide almost completely, but not Instar V crabs. The provision of a hiding space for Instar I crabs was intentional. Each tray was embedded in a larger drawer, and the latter were superposed in 4 columns of 8 drawers. Temperature controlled $\left(4^{\circ} \mathrm{C}\right)$, fresh seawater of salinity ranging from 30.5 to $31.3 \%$ entered the rear of the top drawer and flowed beneath the tray, moving up through its bottom and out through its cover, before cascading down to the next drawer. The flow rate was $41 \mathrm{~min}^{-1}$ to renew each tray's water content every 2 min and maintain the temperature differential between the top and bottom trays to within $0.5^{\circ} \mathrm{C}$. Temperature and salinity during experiments were within the range of values at which juvenile snow crabs are encountered in nature (Slizkin 1982).

Experimental treatments were divided into 2 groups. Four single cohort treatments with either 7, 14, 28 or 56 Instar I crabs per tray tested for density effects on intracohort cannibalism. Six double cohort treatments with 56 Instar I crabs (hereafter called the junior cohort) in the presence of either 1, 3, 6, 9, 12 or 24 Instar V crabs (hereafter called the senior cohort) per tray tested for predator density effects on intercohort cannibalism. The single cohort treatment with 56 Instar I crabs served as a control for the double cohort treatments. The ratio of density in our single cohort treatments ranged from low $(0.1: 1)$ to high $(4.5: 1)$ relative to the observed maximum density of early juveniles in situ at the upper limit of their depth distribution range (see Lovrich et al. 1995). Each of the single and double cohort treatments was replicated 3 times. A control group of 40 individually reared Instar I crabs was placed in 1 tray subdivided by opaque and solid plastic walls into 40 compartments of $30 \mathrm{~cm}^{2}$ bottom area each. For the sake of simplicity, treatments are designated by the ratio of Instar I to Instar V crabs at the onset of the experiment.

One replicate of each of the single cohort treatments and of each of the 4 double cohort treatments with 1, 3, 6 or 9 Instar V crabs was randomly allocated a vertical position in each of the first 3 columns of trays. The fourth column of trays contained the 2 double cohort treatments with 12 or 24 Instar V crabs and the control crabs. On each occasion the trays were checked, they were permuted 1 position vertically. All but 2 treatments were conducted from 23 August to 5 December 1994. Treatments combining 56 Instar I crabs with 1 or 9 Instar V crabs were started on 30 August and continued until 12 December 1994. Instar I crabs averaged 1 wk post-metamorphosis age on both starting dates. The total duration of the experiment was $104 \mathrm{~d}$. Instar $\mathrm{V}$ crabs were acclimated to the trays for $5 \mathrm{~d}$ prior to start of experiment. During this period, they were fed to satiety. Instar I crabs were introduced to the trays on Day 0 of the experiment. During the experiment, each tray was provided with $1.2 \mathrm{~g}$ minced rations of shrimp Pandalus borealis on Monday, of clam Mactromeris stimpsoni on Wednesday and of herring Clupea harengus on Friday. Food was distributed randomly over the entire bottom of the tray. At each feeding period, the presence of leftover food was recorded and the remains were removed by suction.

Replicates and controls were examined daily during Week 1, and subsequently on every second or third day. Behavioral interactions were noted qualitatively. Live crabs were enumerated independently by 2 observers, which compared their counts. If the difference between the 2 counts was $\leq 1$, the number of live crabs was recorded as the largest count. If the 2 counts differed by $\geq 2$, which rarely was the case, then live crabs were again enumerated independently until the counts converged. Dead crabs and exuviae were removed, counted and when possible ascribed to an instar, and their CW was measured to the nearest $0.01 \mathrm{~mm}$ using a vernier caliper. Note that snow crabs do not usually eat cast exoskeletons; thus, exuviae constitute a good record of molting.

At the end of the experiment, the trays were disassembled. All surviving crabs from the junior cohort were counted and ascribed to an instar, and the number of missing limbs and CW were determined. The same person measured and assigned crabs to instars throughout the experiment. The composite sizefrequency distribution derived from measurements of exuviae and dead or live crabs revealed 3 quite conspicuous modes representing Instars I to III (Fig. 1) and therefore, instar misclassification is unlikely.

Data analysis. Statistical analyses were performed using the SAS (1999) 8.02 software package. Normality was verified with Shapiro-Wilk's $W$-test and homoscedasticity was verified with Brown and Forsythe's test. For most statistical tests, differences were considered significant when $p<0.05$; however, in the case of multiple pairwise comparisons with a $t$-test, the threshold for significance was set at $0.05 / k$, where $k$ is the number of comparisons. Among replicate variation was considered for statistical analyses of survival and distribution of crabs by instar at end of experiment, but data from replicates were pooled by treatment for analyses of molt schedules, of mean CW by instar and of number of missing limbs at end of experiment owing to small sample sizes for some individual replicates.

To describe the molt schedule of crabs of the junior cohort, the cumulative number of Instar I exuviae on each sampling day was expressed as a proportion of the total number of Instar I exuviae retrieved at experiment's end and was modeled by a logistic curve using 


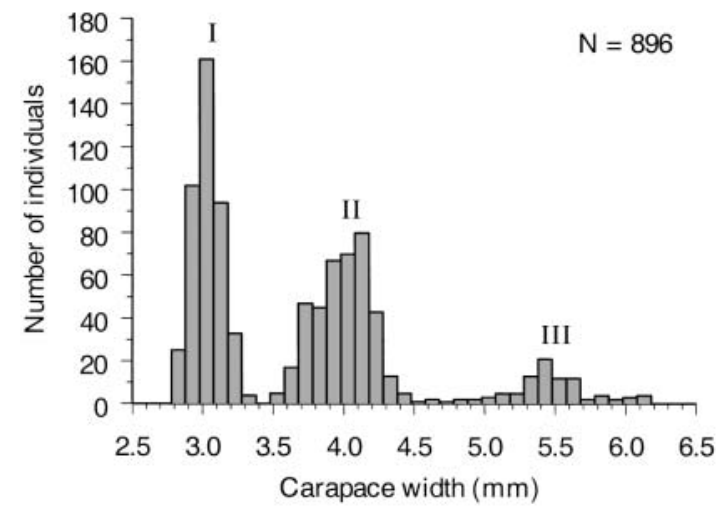

Fig. 1. Chionoecetes opilio. Frequency distribution of carapace width measured on exuviae, dead individuals and survivors of the junior cohort, excepting the controls. Crabs are grouped by $0.1 \mathrm{~mm}$ size classes and instars are identified by roman numerals above modes

pooled data from the 3 replicates of each treatment. The logistic equation we used is a slight modification of Somerton's (1980):

$$
Y=\frac{\mathrm{e}^{A+B X}}{1+\mathrm{e}^{A+B X}}
$$

where $Y$ is the cumulative proportion of Instar I exuviae, $X$ is the number of days elapsed since the start of the experiment, and $A$ and $B$ are undetermined parameters. The linearized form of this equation is:

$$
\ln \left(\frac{Y}{1-Y}\right)=A+B X
$$

The $X$ value corresponding to any $Y$ can be calculated from:

$$
\hat{X}=\frac{\ln \left(\frac{Y}{1-Y}\right)-A}{B}
$$

which evaluated at a $Y$ value of 0.5 provides an estimate of the number days elapsed when $50 \%$ of crabs had molted:

$$
\hat{X}_{0.5}=\frac{-A}{B}
$$

The variance of $\hat{X}_{0.5}$ (fitting error) can be estimated as:

$$
\operatorname{Var}\left(\hat{X}_{0.5}\right)=\left(\frac{A}{B}\right)^{2}\left[\frac{\operatorname{Var}(A)}{A^{2}}+\frac{\operatorname{Var}(B)}{B^{2}}-\frac{2 \times \operatorname{Cov}(A, B)}{A B}\right]
$$

where Var and Cov are the variance and covariance, respectively. The values of $A, \operatorname{Var}(A), B$ and $\operatorname{Var}(B)$ were estimated using the LOGISTIC/covb procedure in the SAS software. Finally, comparisons of $\hat{X}_{0.5}$ between different pairs $(i, j)$ of treatments were made with the following Student $t$-test:

$$
t=\frac{\hat{X}_{0.5}^{(i)}-\hat{X}_{0.5}^{(j)}}{\sqrt{\operatorname{Var}\left(\hat{X}_{0.5}^{(i)}\right)+\operatorname{Var}\left(\hat{X}_{0.5}^{(j)}\right)}} \sim \mathrm{N}(0,1)
$$

The experiment was terminated while crabs of the junior cohort were molting from Instar II to III. Due to this interruption, the temporal pattern of second molt could not be modeled by a logistic regression. Instead, the cumulative number of Instar II exuviae on each sampling day was expressed as a percentage of the initial number of Instar I. Model I regression was used to describe the relationship between percentage of Instar I molted to Intstar III over time in each treatment; the dependent variable was transformed as:

$$
Y^{\prime}=\arcsin \sqrt{(Y / 100)}
$$

to ensure linearity and normality. The first 2 zero observations for cumulative percentage were included in regression models. ANCOVA was used to test for heterogeneity among treatments in the slopes of the percentage of Instar I having molted to Instar III among treatments (Snedecor \& Cochran 1989).

Relationships between size and day at molt for any given instar were determined by linear regression or Spearman correlation of $\mathrm{CW}$ on days elapsed since start of experiment. Regressions were performed separately for crabs of the junior cohort from single and double cohort treatments and slopes were compared among treatments by ANCOVA. When homogeneity of slopes was demonstrated, we proceeded to compare elevations by ANCOVA.

The effect of Instar I or V initial density on survival and instar composition of the junior cohort at experiment's end was assessed separately for single and double cohort treatments by 1-way ANOVA. When a significant effect was detected, Tukey's HSD and Dunnett's multiple comparisons were applied to compare single cohort treatments among themselves and to compare double cohort treatments with the control, respectively. Mean CW by instar for live crabs or for accumulated exuviae at experiment's end was also compared among single or double cohort treatments by ANOVA. However, the CW of Instar II exuviae from the double cohort treatments was compared with a Student $t$-test because only treatments 56:0 and 56:1 had more than 1 datum. After an ANOVA or a $t$-test demonstrated homogeneity of mean CW among single and double cohort treatments, an overall mean CW by instar was calculated for each group of treatments and the 2 resulting means were compared with Student's $t$-test. Assumptions of normality and homoscedasticity were virtually always met; in 2 cases where these assumptions were violated, comparisons between groups were performed using the Mann-Whitney $U$-test. Finally, the Pearson $\chi^{2}$ test on pooled data from the 3 replicates of each treatment was used to compare the percentage of intact survivors and the percentage of dead crabs retrieved among single and double cohort treatments. 


\section{RESULTS}

\section{Temporal pattern of molting}

Crabs of the junior cohort molted up to 2 times during the experiment (Fig. 2). In single cohort treatments, molting from Instar I to II was initiated 29 to $34 \mathrm{~d}$ after the start of the experiment (Fig. 2A). The $50 \%$ mark for cumulative proportion of Instar I exuviae was reached at about Day 44 in the 7:0 treatment, significantly sooner than the 47 to $48 \mathrm{~d}$ recorded in the 14:0, 28:0 and 56:0 treatments (Table 1). Molting from Instar II to III started earlier in the 7:0 and 14:0 treatments than in the 28:0 and 56:0 treatments, i.e. around Day 72 to 76 compared with around Day 79 to 83 (Fig. 2A). Moreover, the slope of the regression of cumulative number of Instar II exuviae on sampling day was steeper in the $7: 0$ treatment than in all other single cohort treatments, and was steeper in the 14:0 and 28:0 treatments than in the 56:0 treatment (Table 2). Because the onset and rate of second molting differed among treatments, the average percentage of initial number of Instar I crabs that had molted to Instar III at experiment's end was about $62 \%$ in the $7: 0$ treatment, $43 \%$ in the $14: 0$ treatment, $24 \%$ in the 28:0 treatment and only $16 \%$ in the 56:0 treatment (Fig. 2A). During both molting events, controls were as slow or even slower to molt than crabs in the densest (56:0) single cohort treatment (Fig. 2A).

In the double cohort treatments, no crabs of the junior cohort survived long enough to undergo a first molt in the 56:12 and 56:24 treatments (see below), and only 1 crab in the 56:9 treatment molted from Instar I to II on Day 39 to 41 . In the remaining double cohort treatments, crabs of the junior cohort began to molt from Instar I to II on Days 25 to 27 in the $56: 1$ treatment and on Days 39 to 43 in the 56:3 and 56:6 treatments (Fig. 2B). Fifty percent of Instar I exuviae were retrieved from treatments $56: 1,56: 3$ and $56: 6$ on Days 60 to 61, which is much later than the $48 \mathrm{~d}$ determined for the 56:0 control ( $p<0.001$; Table 3). This same pattern of severely delayed molting in the
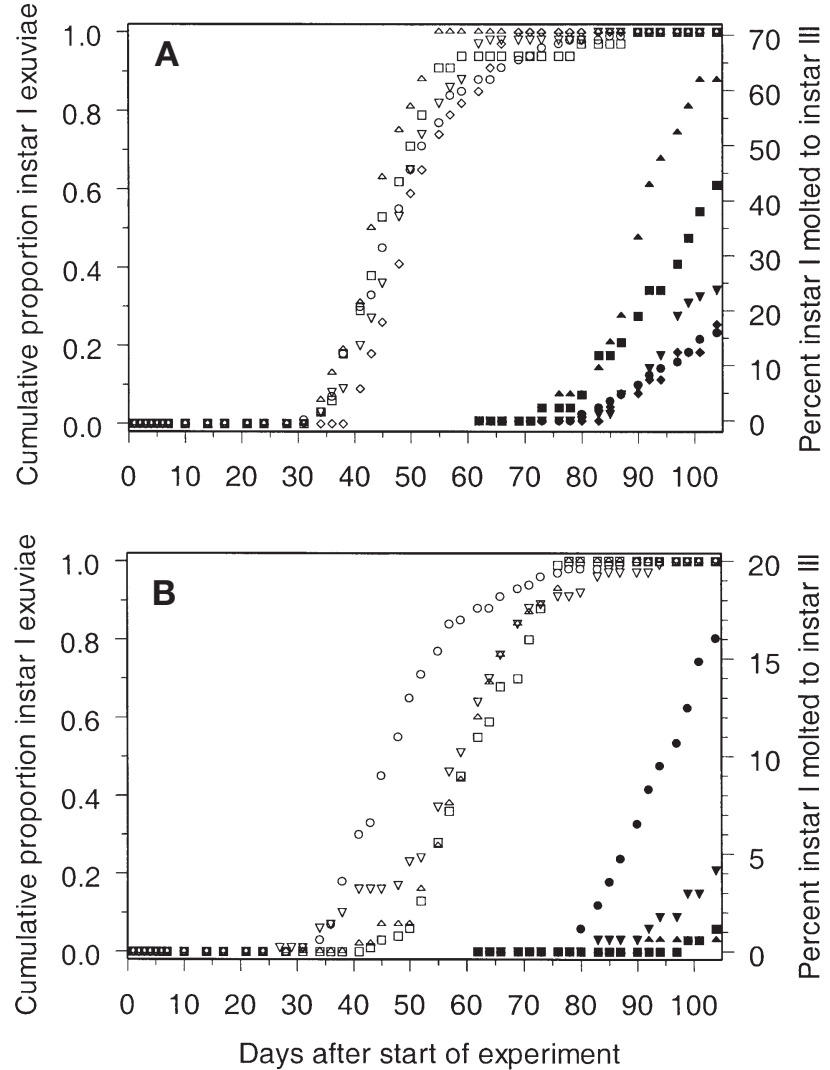

Fig. 2. Chionoecetes opilio. Temporal pattern of cumulative proportion of Instar I exuviae (indicating the molt schedule from Instar I to II, open symbols, left $y$-axis) and cumulative percentage of initial number of Instar I having molted to Instar III (based on retrieved Instar II exuviae, solid symbols, right $y$ axis). Data are pooled from the 3 replicates of each treatment. (A) Single cohort treatments: 7 Instar I:0 Instar V $(\Delta, \mathbf{\Delta}) ; 14: 0$ $(\square, \boldsymbol{\square}) ; 28: 0(\nabla, \nabla) ; 56: 0(0, \bullet)$; control crabs $(\diamond, \bullet)$. (B) Double cohort treatments: 56:0 $(0, \bullet) ; 56: 1(\nabla, \mathbf{v}) ; 56: 3(\square, \boldsymbol{\square}) ; 56: 6(\Delta, \mathbf{\Delta})$

presence of the senior cohort was repeated during the second molting event. Crabs of the junior cohort began to molt from Instar II to III on Days 81 to 83 in the 56:1 treatment and on Days 91 to 99 in the 56:3 and 56:6 treatments, compared to about Days 79 to 80

Table 1. Chionoecetes opilio. Comparison of the mean time $\left(\hat{X}_{0.5}\right.$ and variance: var $\left.\hat{X}_{0.5}\right)$ at which $50 \%$ of the individuals had molted from Instar I to II among treatments with different initial numbers of Instar I (see Fig. 2A). $\hat{X}_{0.5}$ is derived from Eq. (1), where $Y$ is the cumulative proportion of total retrieved Instar I exuviae and $X$ is the number of days elapsed since start of experiment. Data from the 3 replicates of each treatment were pooled for analyses. Post hoc comparisons were performed with a $t$-test

\begin{tabular}{|c|c|c|c|c|c|c|c|}
\hline \multirow[t]{2}{*}{ Instar I (n) } & \multicolumn{2}{|c|}{ Logistic parameters } & \multicolumn{2}{|c|}{ Days to $50 \%$ molt } & \multicolumn{3}{|c|}{ Post hoc comparisons } \\
\hline & A & B & $\hat{X}_{0.5}$ & $\operatorname{var} \hat{X}_{0.5}$ & 7 & 14 & 28 \\
\hline 7 & -13.04 & 0.30 & 43.6 & 0.1 & - & - & - \\
\hline 14 & -7.46 & 0.16 & 46.9 & 0.2 & $<0.001$ & - & - \\
\hline 28 & -10.21 & 0.21 & 47.9 & 0.1 & $<0.001$ & $0.044^{\mathrm{ns}}$ & - \\
\hline 56 & -7.47 & 0.15 & 48.4 & 0.2 & $<0.001$ & $0.010^{\mathrm{ns}}$ & $0.424^{\mathrm{ns}}$ \\
\hline
\end{tabular}


Table 2. Chionoecetes opilio. Comparison of the slope of the regression of the cumulative percentage of having molted from Instar I to III over time among treatments with different initial numbers of Instar I (see Fig. 2A for raw data). $Y$ is the arcsinetransformed percentage of retrieved Instar II exuviae relative to initial number of Instar $\mathrm{I}_{i}$ the regression equation is $Y=A+B X$, where $X$ is the number of days elapsed since start of experiment. Data from the 3 replicates of each treatment were pooled for analyses. Post hoc comparisons of slopes were performed with a $t$-test after ANCOVA demonstrated heterogeneity of slopes

\begin{tabular}{|c|c|c|c|c|c|c|c|c|}
\hline \multirow[t]{2}{*}{ Instar I (n) } & \multicolumn{2}{|c|}{ Regression parameters } & \multicolumn{3}{|c|}{ Statistics } & \multicolumn{3}{|c|}{ Post hoc comparisons } \\
\hline & $A$ & $B$ & $\mathrm{n}$ & $\mathrm{p}$ & $\mathrm{r}^{2}$ & 7 & 14 & 28 \\
\hline 7 & -2.172 & 0.031 & 15 & $<0.001$ & 0.97 & - & - & - \\
\hline 14 & -1.397 & 0.020 & 16 & $<0.001$ & 0.98 & $<0.001$ & - & - \\
\hline 28 & -1.738 & 0.022 & 12 & $<0.001$ & 0.98 & $<0.001$ & $0.290^{\mathrm{ns}}$ & - \\
\hline 56 & -1.100 & 0.015 & 13 & $<0.001$ & 0.96 & $<0.001$ & $<0.001$ & $<0.001$ \\
\hline
\end{tabular}

Table 3. Chionoecetes opilio. Comparison of the mean time (and variance: var ) at which $50 \%$ had molted from Instar I to II among treatments with a constant initial number of Instar I and different initial numbers of Instar V (see Fig. 2B). Refer to Table 1 for explanation of logistic parameters and statistical procedure

\begin{tabular}{|c|c|c|c|c|c|c|c|}
\hline \multirow{2}{*}{$\begin{array}{l}\text { Treatment } \\
\text { Instar I:InstarV }\end{array}$} & \multicolumn{2}{|c|}{ Logistic parameters } & \multicolumn{2}{|c|}{ Days to $50 \%$ molt } & \multicolumn{3}{|c|}{ Post hoc comparisons } \\
\hline & A & B & $\hat{X}_{0.5}$ & $\operatorname{var}\left(\hat{X}_{0.5}\right)$ & $56: 0$ & 56:1 & $56: 3$ \\
\hline $56: 0$ & -7.47 & 0.15 & 48.4 & 0.2 & - & - & - \\
\hline $56: 1$ & -7.83 & 0.13 & 60.6 & 0.2 & $<0.001$ & - & - \\
\hline $56: 3$ & -12.85 & 0.21 & 61.5 & 0.1 & $<0.001$ & $0.078^{\mathrm{ns}}$ & - \\
\hline $56: 6$ & -12.63 & 0.21 & 60.3 & 0.1 & $<0.001$ & $0.693^{\mathrm{ns}}$ & 0.005 \\
\hline
\end{tabular}

in the 56:0 treatment (Fig. 2B). At the experiment's end, $16 \%$ of the initial number of Instar I crabs had molted to Instar III in the 56:0 treatment, compared to only $4 \%$ in the $56: 1$ treatment and $1 \%$ in the $56: 3$ and 56:6 treatments (Fig. 2B).

Within the junior cohort, larger crabs tended to molt sooner than smaller crabs. In single cohort treatments, there was a negative trend between $\mathrm{CW}$ and day of

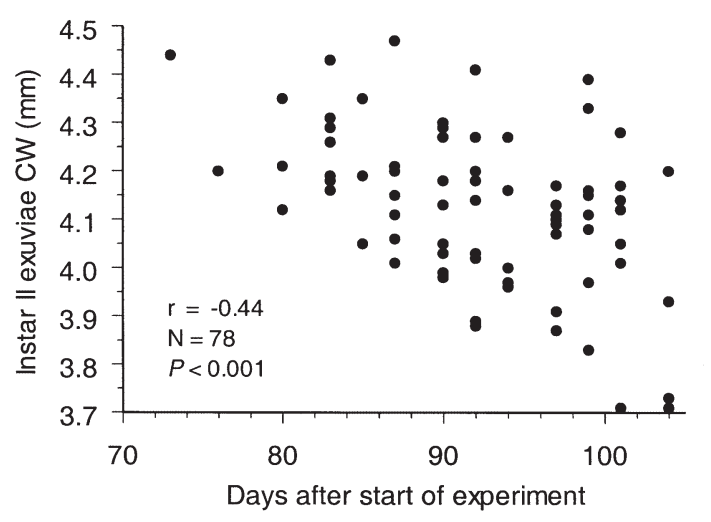

Fig. 3. Chionoecetes opilio. Carapace width on day of collection of Instar II exuviae pooled from all single cohort treatments but excluding control crabs collection of exuviae that was marginally not significant for Instar I (ANCOVA, $\mathrm{n}=230, \mathrm{p}=0.080$ ), but that was highly significant for Instar II (ANCOVA, $\mathrm{n}=78, \mathrm{p}<$ 0.001; see Fig. 3 for data plot and overall correlation). In double cohort treatments 56:1,56:3 and 56:6, there was also a negative relationship between $\mathrm{CW}$ and collection day of Instar I exuviae (ANCOVA, $\mathrm{n}=177, \mathrm{p}=0.012$ ). The number of Instar II exuviae retrieved from double cohort treatments was too small for assessing the relationship between CW and molting rank.

\section{Survival over time}

In the single cohort treatments, crabs tended to remain in the open and this facilitated their enumeration for the determination of survival. In the double cohort treatments most crabs of the junior cohort were in hiding and this made enumeration difficult. Careful examination of the recess in the tray side wall was required to detect hidden crabs.

Proportional survival of crabs in the junior cohort followed the same temporal pattern and was similar in magnitude across the 4 single cohort treatments (Fig. 4). Mortality was negligible during the first half of the experiment, but increased slightly thereafter. By 


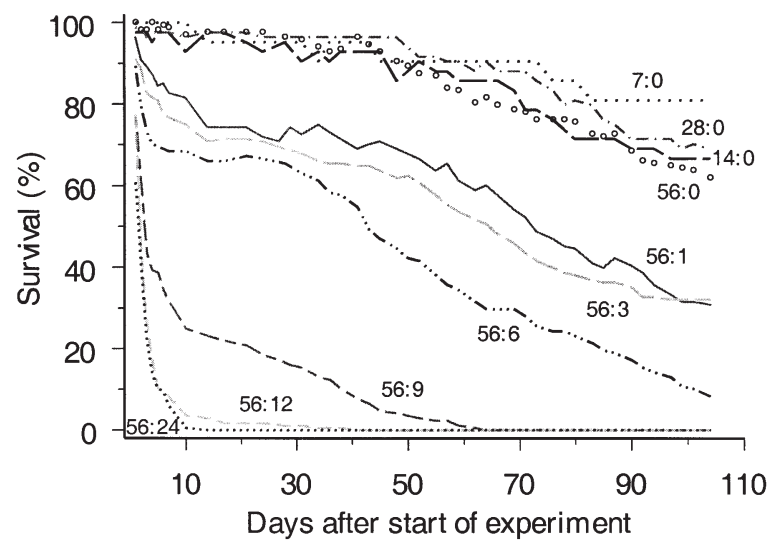

Fig. 4. Chionoecetes opilio. Proportional survival over time of crabs stocked as Instar I in relation to initial numbers of Instars I and V (see ratios in graph). Lines join individual data points representing mean survival by sampling date derived from the 3 replicates of each treatment. Individual data points, instead of a line, are presented for the 56:0 treatment to illustrate sampling frequency

contrast, in double cohort treatments, the junior cohort lost many individuals over the first $5 \mathrm{~d}$ of the experiment (Fig. 4). Proportional survival was inversely related to the number of Instar V crabs: in the 56:12 and 56:24 treatments, survival declined to $10 \%$ by Day 5. In the 56:24 treatment, all crabs of the junior cohort died within $14 \mathrm{~d}$. In the remaining double cohort treatments, the initial period of high mortality was followed from about Day 5 to 10 to about Day 35 to 50 by a period of null to low mortality rate during which the last surviving junior crab of the 56:12 treatment died. After this lull, the mortality rate increased again and remained relatively constant; the slope of proportional survival over time being similar or slightly steeper than that observed in single cohort treatments during the second half of the experiment (Fig. 4).

\section{Survival, instar composition, size and condition at end of experiment}

At experiment's end, proportional survival of crabs of the junior cohort was independent of density in the single cohort treatments and was comparable to the $68 \%$ value recorded in the control group (Fig. 5A). However, in double cohort treatments, survival of crabs of the junior cohort was significantly less than observed in the control (56:0) and it declined with increasing density of Instar $\mathrm{V}$ crabs (Fig. 5A). On average, 31 to $32 \%$ of the crabs of the junior cohort survived in the presence of 1 or 3 Instar $\mathrm{V}$ crabs, only $8 \%$ survived in the presence of 6 Instar $V$ crabs and none survived in the presence of 9 or more Instar $\mathrm{V}$ crabs.
There were significant differences among treatments in the distribution of survivors by instar at experiment's end (Fig. 5B). In single cohort treatments, the bulk of survivors was distributed between Instars II and III. Only $3 \%$ of the crabs survived as Instar I in treatments 28:0 and 56:0, while in the remaining treatments, no Instar I crab was left over. The average percentage of Instar II survivors was significantly less in the $7: 0$ and $14: 0$ treatments (24 and $35 \%$, respectively) than in the 28:0 and 56:0 treatments (66 and $76 \%$, respectively) and the percentage of Instar III survivors
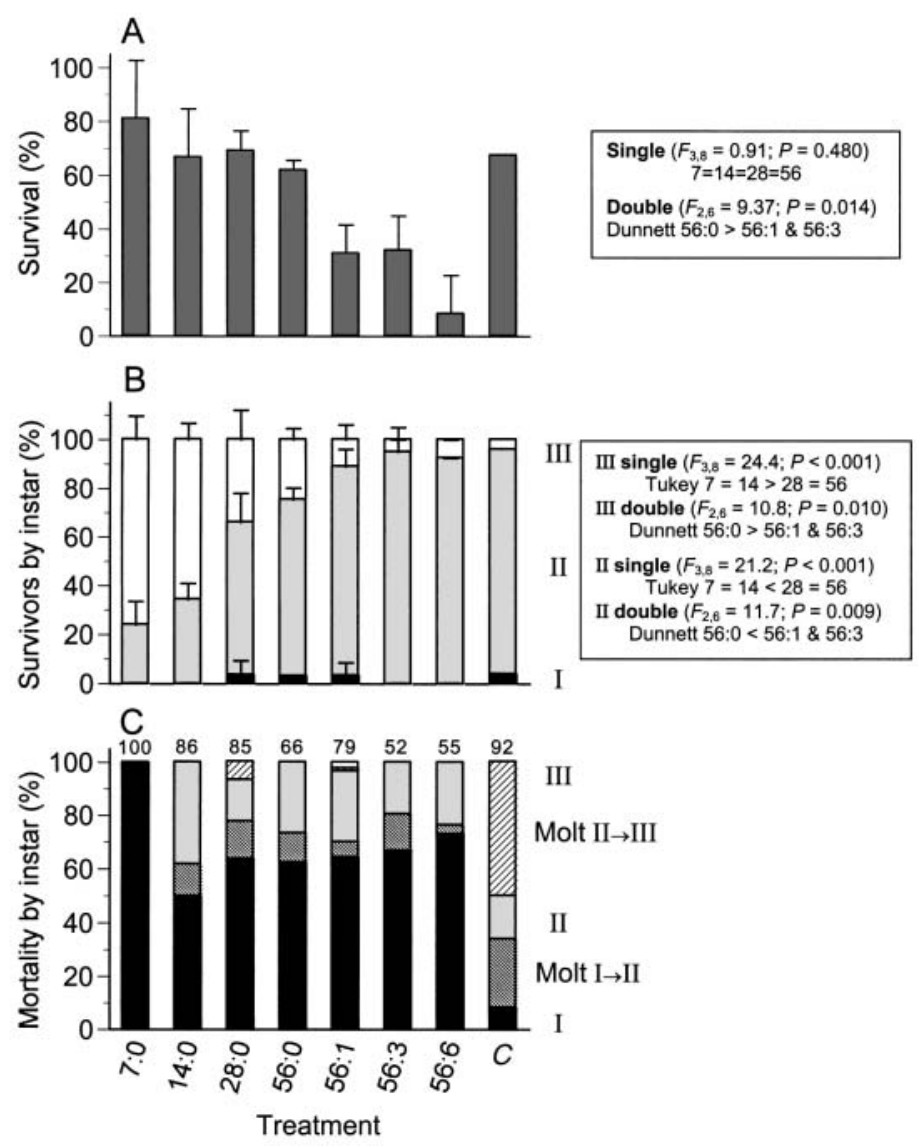

Fig. 5. Chionoecetes opilio. Fate of crabs stocked as Instar I in relation to initial numbers of Instars I and V. Treatments 56:9, 56:12 and 56:24 are not shown because no Instar I crab survived to the end of the experiment. Control group $(C)$ represents 40 individually reared Instar I crabs. (A) Mean percentage of survival. (B) Survivors partitioned by instar. Black fill represents Instar I, gray fill represents Instar II and white fill represents instar III; error bars are $1 \mathrm{SD}$. Boxed information beside Panes A and B are results of ANOVA and of multiple comparisons (Tukey's HSD or Dunnett's $t$-tests with 56:0 as control). Treatment 56:6 was not included in comparisons because 2 of its replicates did not yield survivors. (C) Partitioning of mortality by instar (uniform fill patterns as in Pane B) and molting event (striped fill patterns). Numbers above bars represent the percentage of dead crabs from the junior cohort that were retrieved relative to initial number of Instar I 


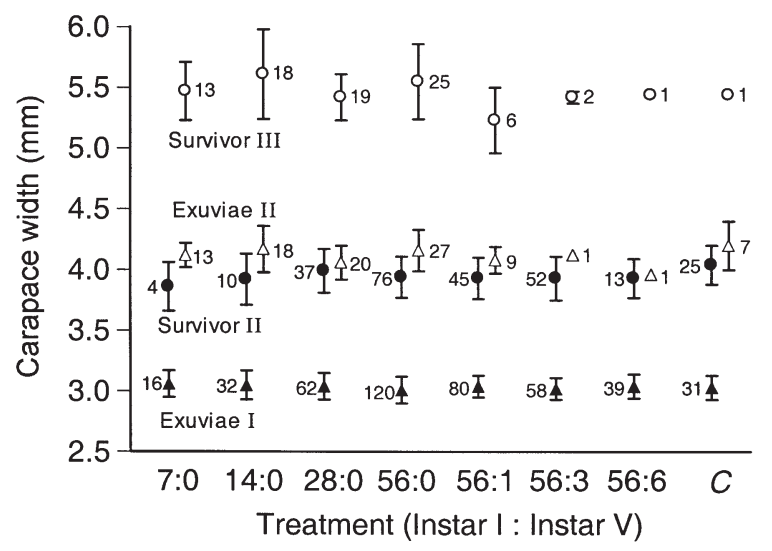

Fig. 6. Chionoecetes opilio. Mean \pm 1 SD of carapace width of Instars I and II exuviae (triangles), and of Instars II and III survivors (circles) by treatment. Control crabs $(C)$ were reared individually. Treatments 56:9, 56:12 and 56:24 are not shown because no crab of the junior cohort survived to experiment's end. The number of carapace(s) measured appears beside each symbol

was complementary. By contrast, in double cohort treatments, 89 to $95 \%$ of survivors of the junior cohort were Instar II at the experiment's end and these percentages were significantly greater than the $76 \%$ observed in the control (56:0). The percentage of surviving control crabs that were Instar II at the experiment's end was equally as high as that observed in the double cohort treatments (Fig. 5B).

Partitioning the mortality events by instar or molt stage for crabs of the junior cohort was somewhat complicated by the discrepancy between the number of crab carcasses that were retrieved and the actual number of dead crabs at experiment's end (see percentages above bars in Fig. 5C). This discrepancy existed in all treatments except the 7:0 treatment, and it tended to increase with density in the single cohort treatments $\left(\chi^{2}\right.$ test, $\mathrm{df}=3, \mathrm{p}=0.099$ ) and with number of Instar $\mathrm{V}$ crabs in the double cohort treatments 56:0, 56:1, 56:3 and 56:6 ( $\chi^{2}$ test, $\left.\mathrm{df}=3, \mathrm{p}<0.001\right)$. Crab carcasses were rarely retrieved from double cohort treatments with more than 6 Instar V crabs and they were usually partially consumed. Hence, crabs that 'disappeared' from treatments were presumably completely consumed. Based on the dead crabs that were retrieved from single and double cohort treatments (Fig. 5C), however, mortality seemed to occur mostly during the intermolt stage (exoskeletons were hard) of Instar I (50 to 100\% depending on treatment) and to a lesser degree of Instar II ( 0 to $39 \%$ depending on treatment). In double cohort treatments from which few or no crab carcasses were retrieved, mortality may be inferred to have occurred only at the intermolt stage of Instar I, because the precipitous decline in survival over the first 5 to $10 \mathrm{~d}$ occurred long before the first molting period commenced (Figs. $2 \& 4$ ). In contrast to the above, $75 \%$ of mortality of control crabs occurred at molting (Fig. 5C).

Carapace width at a given instar was similar across all treatments (Fig. 6). ANOVA on mean CW of Instars I and II exuviae, and on Instar II and III survivors, detected no significant difference in mean CW among single cohort treatments $(p \geq 0.123)$ or among the control and double cohort treatments ( $\mathrm{p} \geq 0.072$ ) (Table 4). Consequently, we calculated an overall average CW for each of the exuviae or survivor groups (Table 4). Instar II survivors were smaller on average than instar II exuviae and the difference in CW between the 2 groups was significant (Mann-Whitney $U$-test, $\mathrm{p}<0.001)$. In the control group at Instar II, the survivors were also smaller than the exuviae (Fig. 6). However, the $\mathrm{CW}$ of pooled exuviae and survivors at Instar II was greater in control crabs (mean \pm SD: 4.07 $\pm 0.18 \mathrm{~mm}$ ) than in crabs from treatments (3.99 \pm $0.19 \mathrm{~mm}$ ) and the difference was significant (MannWhitney $U$-test, $\mathrm{p}=0.019$ ).

The condition of survivors from the junior cohort at the end of the experiment differed among treatments. The percentage of intact survivors (i.e. missing no

Table 4. Chionoecetes opilio. Comparison of carapace width (CW in $\mathrm{mm}$ ) among treatments with different initial numbers of Instar I only (single cohort treatments) and with constant number of Instar I and different numbers of Instar V (double cohort treatments). p values assigned according to 1-factor ANOVA, except when specified ${ }^{\mathrm{b}}$. Mean $(\bar{x})$ and SD of CW were calculated after ANOVA demonstrated no treatment effects

\begin{tabular}{|c|c|c|c|c|c|c|c|c|}
\hline \multirow[t]{2}{*}{ Instar } & \multicolumn{3}{|c|}{$\begin{array}{c}\text { Single cohort } \\
(7: 0,14: 0,28: 0,56: 0)\end{array}$} & \multicolumn{3}{|c|}{$\begin{array}{c}\text { Double cohort } \\
(56: 0,56: 1,56: 3,56: 6)\end{array}$} & \multicolumn{2}{|c|}{ CW } \\
\hline & $F$ & df & $\mathrm{p}$ & $F$ & df & $\mathrm{p}$ & $\bar{x} \pm \mathrm{SD}$ & $\mathrm{n}$ \\
\hline Survivor III & 1.55 & 3,71 & 0.209 & 2.88 & $2^{\mathrm{a}}, 30$ & 0.072 & $5.48 \pm 0.29$ & 84 \\
\hline Exuviae II & 1.99 & 3,74 & 0.123 & $1.31^{\mathrm{b}}$ & $34^{\mathrm{b}}$ & 0.200 & $4.11 \pm 0.16$ & 89 \\
\hline Survivor II & 1.26 & 3,123 & 0.290 & 0.05 & 3,182 & 0.987 & $3.94 \pm 0.17$ & 237 \\
\hline Exuviae I & 1.50 & 3,226 & 0.216 & 1.26 & 3,293 & 0.287 & $3.03 \pm 0.10$ & 407 \\
\hline
\end{tabular}


Table 5. Chionoecetes opilio. Percentage of survivors missing no limbs at the end of the experiment relative to all survivors (N) from the 3 replicates of each treatment. Density effects for single cohort treatments (7:0 to 56:0) and for double cohort treatments (56:1 to 56:6) and their control (56:0) were examined by Pearson $\chi^{2}$ test

\begin{tabular}{|lrr|ccc|}
\hline $\begin{array}{l}\text { Instar I: } \\
\text { Instar V }\end{array}$ & $\begin{array}{c}\text { \% intact } \\
\text { survivors }\end{array}$ & $\mathrm{N}$ & $\chi^{2}$ & $\mathrm{df}$ & $\mathrm{p}$ \\
\hline $7: 0$ & 76.5 & 17 & & & \\
$14: 0$ & 78.6 & 28 & 0.99 & 3 & 0.805 \\
$28: 0$ & 70.7 & 58 & & & \\
$56: 0$ & 76.9 & 104 & & & \\
$56: 1$ & 25.0 & 52 & & & \\
$56: 3$ & 18.2 & $44^{\mathrm{a}}$ & 70.95 & 3 & $<0.001$ \\
$56: 6$ & 7.1 & 14 & & & \\
Controls & 95.8 & 24 & & & \\
anformation lacking for 10 individuals & & \\
\hline
\end{tabular}

limbs) varied in the single cohort treatments from 71 to $79 \%$ and was independent of density; however, in the double cohort treatments, it declined significantly with increasing number of Instar $\mathrm{V}$ crabs from $25 \%$ in the $56: 1$ treatment to $7 \%$ in the 56:6 treatment (Table 5). Injured crabs were missing up to 7 limbs at the 2 highest single cohort densities (28:0 and 56:0), and up to 9 limbs in the presence of 3 Instar V crabs. For comparison, only 1 out of 24 survivors in the control group was injured, and this individual was missing only $1 \mathrm{limb}$.

\section{Food limitation and fate of the senior cohort}

Food rations were never limiting in the single cohort treatments and in the 56:1 and 56:3 double cohort treatments; however, in double cohort treatments with 6 or more Instar $\mathrm{V}$ crabs, the amount of excess food decreased with increasing density and rations were completely consumed between feeding periods in the 56:24 treatment. Depending on treatment, 44 to $83 \%$ of Instar $\mathrm{V}$ crabs molted once during the experiment and this occurred mainly from Day 75 to 100 . Mean survival of Instar $\mathrm{V}$ crabs over the duration of the experiment was high $(100 \%$ in $56: 1,77.8 \%$ in $56: 3$, $94.4 \%$ in $56: 6,92.6 \%$ in $56: 9,80.6 \%$ in $56: 12$ and $86.1 \%$ in 56:24) and seemingly independent of density.

\section{DISCUSSION}

This study has documented in detail the molt and mortality schedules of recently settled snow crabs and assessed their proportional survival, size and condition at the end of a $>3$ mo experimental period, in relation to intracohort density and to the density of larger conspecific juveniles. With respect to the initial hypotheses, we discuss below how the results clearly indicate that: (1) intracohort cannibalism is not a likely population regulatory process; (2) intercohort cannibalism is potentially a major source of mortality which scales in magnitude to the density of predators; and (3) most cannibalism occurred very rapidly after cohorts were mixed and most crabs that were killed were intermolt. We close the discussion by reviewing some of the sublethal effects of competition and cannibalism on growth of recently settled crabs.

\section{Intracohort versus intercohort cannibalism as a source of mortality}

Intracohort cannibalism was demonstrated in our experiment by the fact that dead crabs were not all retrieved from the single cohort treatments. Furthermore, the increasing percentage of 'missing' crabs with growing density (Fig. 5C) suggests that intracohort cannibalism may have been density dependent. However, the current experiment does not allow to resolve whether missing crabs were killed by conspecifics and then eaten, indicating intraspecific predation, or eaten after dying of other causes, indicating intraspecific necrophagy.

Regardless of how crabs died, the current experiment shows that increasing cohort density was not an additional source of mortality for the junior cohort when food was not limiting. Proportional survival of crabs in the single cohort treatments after $104 \mathrm{~d}$ was density independent and similar to survival in the control group (Fig. 5A). Proportional survival of crabs of the senior cohort in the double cohort treatments was also apparently independent of density, even when food was limiting. There is no indication from our data that crabs from the junior or the senior cohort were particularly vulnerable to intraspecific predation at or soon after molting. Larger individuals tended to molt sooner than smaller individuals of a snow crab cohort (Fig. 3), as has been noted in the American lobster Homarus americanus (James-Pirri \& Cobb 2000) and in larger snow crabs (Rondeau \& Sainte-Marie 2001). Such a behavior in conjunction with rather high temporal synchrony of molting within cohorts (Fig. 2) may be adaptive to reducing intracohort predation (Jonsson \& Edsman 1998).

Although intracohort predation was probably not a major additional source of mortality in our single cohort treatments, agonistic behavior may have precipitated mortality of vulnerable or weaker crabs. Limb autotomy is a defense against predation (Lawton 1989, Juanes \& Smith 1995) and therefore, the much greater 
proportion of crabs missing at least 1 limb in single cohort treatments compared to the control group strongly suggests that a dominance hierarchy became established among recently settled crabs, as in other crustacean decapod species (e.g. James-Pirri \& Cobb 1999). Also, mortality occurred sooner in the treatments than in the control group because crabs died mainly during Instar I intermolt in treatments compared to first and second periods of ecdysis in the control group (Fig. 5C). The similar magnitude of mortality but the very different partitioning of mortality over time between single cohort treatments and controls suggests the possibility that weaker crabs that would not have survived molting were killed or died prematurely from injury in their early premolt stage, which cannot be distinguished from intermolt by cursory visual examination.

The current experiment provides strong experimental support for the field-based inference that regulation of a year's cohort by older cohorts established on settlement grounds may be important for snow crab recruitment dynamics (reviewed in Sainte-Marie et al. 1996). The pattern of immediate, sharp decline in proportional survival of Instar I crabs in the double cohort treatments is in stark contrast to the very high survival observed initially in the single cohort treatments (Fig. 4), and it occurred even though Instar I crabs could shelter and Instar V crabs were sated at the onset of the experiment. This finding is consistent with Eggleston \& Armstrong's (1995) conclusion that the density of Instar I crabs may become decoupled from settlement intensity over extremely small time scales. Massive mortality of crabs at settlement or very soon after has been documented and attributed to cannibalism, for example in the grapsid crab Hemigrapsus penicillatus (Kurihara \& Okamoto 1987), the Dungeness crab Cancer magister (Fernández et al. 1993a), and the blue crab Callinectes sapidus (Moksnes et al. 1997). Moreover, our experiment demonstrated that mortality was proportional to predator density (Figs. 4 $\& 5)$. There was no evidence that interference competition among Instar $\mathrm{V}$ crabs afforded the junior cohort any refuge from predation at higher predator densities, which is similar to the results of Fernández \& Castilla (2000).

Intercohort predation is probably much more important than intracohort predation as a population regulatory factor in the snow crab. This interpretation is consistent with Polis' (1981) review of various cannibalistic species and recent studies on other brachyuran crabs (Moksnes et al. 1997, Luppi et al. 2001). Smaller crabs have weaker cuticles and larger crabs have stronger chelae; therefore, the former are vulnerable to intercohort predation even during intermolt (Dutil et al. 2000). Instar V snow crabs (age 2 yr) have a much smaller intrinsic predation rate on Instar I crabs than larger juvenile conspecifics up to $36 \mathrm{~mm} \mathrm{CW}$ (age 4 yr) which also co-occur with recently settled crabs (Lovrich \& Sainte-Marie 1997). Therefore, the current experiment may have underestimated both the rapidity and magnitude of decimation of a new year class in situ under some circumstances. On the other hand, the greater structural complexity of natural snow crab habitat may attenuate the effects of intraspecific predation (see for example Luppi et al. 2001).

\section{Sublethal density and cannibalism effects on growth}

The rate of crustacean growth is a function of 2 components, molt increment and intermolt period, which are affected by intrinsic and environmental factors (Hartnoll 1982). In our experiment, the molt increments of crabs of the junior cohort were insensitive to density of recently settled crabs or of larger conspecifics. Indeed, CW at Instars I, II and III, and by deduction, the molt increment from Instar I to II and from Instar II to III, did not vary significantly among treatments (Table 4, Fig. 6). However, the molt schedule of the junior cohort differed among treatments demonstrating that intermolt period was influenced by conspecific density or predation risk (also see Jonsson \& Edsman 1998). In the single cohort treatments, the first molt occurred progressively later as density increased, although the differences were small (Table 1). This pattern was exacerbated at the second molt: the combination of later onset and slower rate of molting with increasing density (Table 2) resulted in a negative trend between the percentage of Instar I crabs having reached Instar III and treatment density (Fig. 2A). This inverse relationship, considering that survival was not statistically different among single cohort treatments, represents clear evidence that increasing density incurred later molting (as confirmed by the distribution of survivors by instar at experiment's end; Fig. 5B). In double cohort treatments, the presence of larger conspecifics resulted in a further considerable delay in the first and second molt of the juvenile cohort (Fig. 2B).

The density and predator dependent delays observed in molting and-by inference-the longer intermolt periods, could potentially result from 2 nonexclusive processes. Firstly, environmental stressors may activate production of a molt-inhibiting hormone secreted in the eyestalks of crabs that depresses levels of circulating ecdysteroids which are required for molting (Bliss \& Boyer 1964). This was demonstrated experimentally by Mattson \& Spaziani (1985) with Cancer antennarius: two 30 min periods of leg-tapping (the stressor) administered daily reduced ecdysteroid 
levels in intact crabs to $20 \%$ of controls within $14 \mathrm{~d}$, but had no effect on de-eyestalked crabs. In our experiment, crowding and the presence of conspecific predators may have acted as environmental stressors, possibly reducing or slowing the increase of ecdysteroid levels and contributing to delay molting. A molt delay will be beneficial to the crab if the environmental stressor can reduce the crab's fitness and molting makes the crab even more vulnerable to, or reduces its chances of evading, the stressor (for example, due to lesser mobility). Conversely, longer term costs of delayed molting, such as reduced growth and survival, may progressively offset the benefits as the delay increases and therefore, should constrain the upper time limit for behavior-mediated molt delay (for discussions pertaining to the impact of delayed metamorphosis see Pechenik 1990, Gebauer et al. 1999).

Secondly, intermolt duration may increase when food intake is reduced as demonstrated in controlled feeding experiments with a variety of crustaceans (e.g. Laval 1975, Mohamedeen \& Hartnoll 1989, Oh \& Hartnoll 2000). In the American lobster Homarus americanus, it is specifically the proecdysis $\left(\mathrm{D}_{0}\right)$ stage which is prolonged by reduced feeding (Aiken 1980, Cobb et al. 1982); however, this stage cannot be discerned from the true intermolt $(\mathrm{C})$ stage by visual examination alone. The reduction of food intake may be a density dependent effect resulting from competition for food among similarly sized individuals, which is a remote possibility in our single cohort treatments because food was never limiting. However, reduced food intake may also result from appetite suppression due to behavioral conditioning or feeding inhibition caused by intense and asymmetric agonistic interactions (Cobb et al. 1982). This could explain the severe molt delay seen in the double cohort treatments: the presence of even 1 Instar $\mathrm{V}$ crab reduces all members of the junior cohort to the rank of subordinate, forces them into hiding and reduces their feeding opportunities, thereby delaying ecdysis in all treatments as we observed during the first molt. If the reduction in food intake is relatively small, the intermolt period may increase with no negative effect on molt increment (Chittleborough 1975), as was seen in the current study.

Limb autotomy can also modify the intermolt period of crabs; the effect depends on the number of limbs that are lost and on the timing of the loss with respect to the molt cycle (review in Skinner 1985). Multiple autotomy usually precipitates molting or is neutral when it occurs before proecdysis $\left(\mathrm{D}_{0}\right.$ stage), delays molting when it occurs between $D_{0}$ and apolysis $\left(D_{1}\right)$, and has no effect on the molt interval when it occurs after $D_{1}$ (Skinner 1985, Smith 1990). Complete regeneration of lost limbs may require several molts in snow crab (Miller \& Watson 1976), but its effect on the molt interval is unknown. In the blue crab Callinectes sapidus, regeneration does not appear to modify the molt interval, although it may reduce the molt increment (Smith 1990). Autotomy was probably not a factor in delayed molting in our single cohort treatments, because the percentage of intact individuals was generally high and did not vary significantly among treatments (Table 5). In the double cohort treatments, the high prevalence and intensity of limb losses may or may not have a been a factor in the large delay for molting depending on when losses occurred. Certainly, however, limb loss would have detrimental effects on crab fitness by impairing their ability to forage and avoid predators (Juanes \& Smith 1995).

The growth pattern of crabs in the control group was unexpected. Controls were larger than treatment crabs at Instar II, but not at Instar I, indicating that individually reared crabs had larger molt increments than communally reared crabs. However, in comparison to the various single cohort treatments, crabs of the control group were as late to molt from Instar I to II as crabs from the 56:0 treatment (Fig. 2), and this finding is in contradiction with the trend of increasing molt delay with increasing density. Jonsson \& Edsman (1998) reported a similar pattern in the crayfish Pacifastacus leniusculus, while Chittleborough (1975) observed in the spiny lobster Panulirus cygnus that isolated individuals were more active and molted less frequently than communally reared individuals presumably due to greater energy expenditure.

In conclusion, mortality of recently settled snow crabs was high in the presence of larger conspecifics due to cannibalism, but was low in their absence. Moreover, mortality from cannibalism occurred swiftly after cohorts were mixed, even though excess high quality alternative food was available; mortality was directly proportional to the density of larger conspecifics. The risk of predation forced recently settled crabs into hiding and severely delayed their growth schedule, and the prevalence and intensity of limb loss by recently settled crabs increased with increasing density of larger conspecifics. Such sublethal effects may continue to reduce year class strength over the long term. However, we recognize that our laboratory results cannot be extrapolated indiscriminately to the field. For example, greater habitat complexity may provide early juveniles with more refuge from cannibalism and interspecific predation risks may modify the behavior and predatory efficiency of larger conspecifics. Nevertheless, the current experiment reinforces the view that predation on recently settled crabs by older juvenile cohorts may be an important regulatory process for snow crab and other crab populations. 
Acknowledgements. We are especially grateful to J. M. Sévigny for assistance during the experiment, and to F. Hazel and Y. Gauthier for general technical support. The planning of this experiment benefited from comments from G. A. Lovrich. We thank G. Daigle for help with the statistical analyses and M. Dionne, J. D. Dutil and 2 anonymous reviewers for constructive comments on the manuscript. Financial support for the experiment and data analysis came from the DFO's Federal Development Plan for Quebec Fisheries (FDPQF) and Integrity II.

\section{LITERATURE CITED}

Aiken DE (1980) Molting and growth. In: Cobb JS, Phillips BF (eds) The biology and management of lobsters. Academic Press, New York, p 91-163

Banks J, Dinnel P (2000) Settlement behavior of Dungeness crab (Cancer magister Dana, 1852) megalopae in the presence of the shore crab, Hemigrapsus (Decapoda, Brachyura). Crustaceana 73:223-234

Bliss DE, Boyer JR (1964) Environmental regulation of growth in the decapod crustacean Gecarcinus lateralis. Gen Comp Endocrinol 4:15-41

Botsford LW, Hobbs RC (1995) Recent advances in the understanding of cyclic behavior of Dungeness crab (Cancer magister) populations. ICES Mar Sci Symp 199:157-166

Castro P (1978) Settlement and habitat selection in the larvae of Exhinoecus pentagonus (A. Milne Edwards), a brachyuran crab symbiotic with sea urchins. J Exp Mar Biol Ecol 34:259-270

Chittleborough RG (1975) Environmental factors affecting growth and survival of juvenile western rock lobsters, Panulirus longipes (Milne Edwards). Aust J Mar Freshw Res 26:177-196

Christy JH (1989) Rapid development of megalopae of the fiddler crab Uca pugilator reared over sediment: implications for models of larval recruitment. Mar Ecol Prog Ser 57:259-265

Cobb JS, Tamm GR, Wang D (1982) Behavioral mechanisms influencing molt frequency in the American lobster, Homarus americanus, Milne Edwards. J Exp Mar Biol Ecol 62:185-200

Comeau M, Conan GY, Maynou F, Robichaud G, Therriault JC, Starr M (1998) Growth, spatial distribution, and abundance of benthic stages of the snow crab (Chionoecetes opilio) in Bonne Bay, Newfoundland, Canada. Can J Fish Aquat Sci 55:262-279

Conan GY, Starr M, Comeau M, Therriault JC, Maynou i Hernàndez FX, Robichaud G (1996) Life history strategies, recruitment fluctuations, and management of the Bonne Bay Fjord Atlantic snow crab (Chionoecetes opilio). In: High latitude crabs: biology, management, and economics. Lowell Wakefield Fish Symp Ser, University of Alaska, Fairbanks, Sea Grant Coll Prog Rep 96-02, p 59-97

Dutil JD, Munro J, Péloquin M (1997) Laboratory study of the influence of prey size on vulnerability to cannibalism in snow crab (Chionoecetes opilio O. Fabricius, 1780). J Exp Mar Biol Ecol 212:81-94

Dutil JD, Rollet C, Bouchard R, Claxton WT (2000) Shell strength and carapace size in non-adult and adult male snow crab (Chionoecetes opilio). J Crustac Biol 20:399-406

Eggleston DB, Armstrong DA (1995) Pre- and post-settlement determinants of estuarine Dungeness crab recruitment. Ecol Monogr 65:193-216

Elner RW, Beninger PG (1995) Multiple reproductive strategies in snow crab, Chionoecetes opilio: physiological path- ways and behavioral plasticity. J Exp Mar Biol Ecol 193: 93-112

Fernández M (1999) Cannibalism in Dungeness crab Cancer magister: effects of predator-prey size ratio, density, and habitat type. Mar Ecol Prog Ser 182:221-230

Fernández M, Castilla JC (2000) Recruitment of Homolaspis plana in intertidal habitats of central Chile and implications for the current use of management and marine protected areas. Mar Ecol Prog Ser 208:157-170

Fernández M, Armstrong D, Iribarne O (1993a) First cohort of young-of-the-year Dungeness crab, Cancer magister, reduces abundance of subsequent cohorts in intertidal shell habitat. Can J Fish Aquat Sci 50:2100-2105

Fernández M, Iribarne O, Armstrong D (1993b) Habitat selection by young-of-the-year Dungeness crab Cancer magister and predation risk in intertidal habitats. Mar Ecol Prog Ser 92:171-177

Forward RB Jr, Frankel DA, Rittschof D (1994) Molting of megalopae from the blue crab Callinectes sapidus: effects of offshore and estuarine cues. Mar Ecol Prog Ser 113: $55-59$

Gebauer P, Paschke K, Anger K (1999) Costs of delayed metamorphosis: reduced growth and survival in early juveniles of an estuarine grapsid crab, Chasmagnathus granulata. J Exp Mar Biol Ecol 238:271-281

Gebauer P, Paschke K, Anger K (2002) Metamorphosis in a semiterrestrial crab, Sesarma curacaoense: intra- and interspecific settlement cues from adult odors. J Exp Mar Biol Ecol 268:1-12

Hartnoll RG (1982) Growth. In: Abele LG (ed) The biology of Crustacea. Academic Press, New York, p 111-196

Hines AH, Ruiz GM (1995) Temporal variation in juvenile blue crab mortality: nearshore shallows and cannibalism in Chesapeake Bay. Bull Mar Sci 57:884-901

Iribarne O, Fernández M, Armstrong D (1994) Does space competition regulate density of juvenile Dungeness crab Cancer magister Dana in sheltered habitats? J Exp Mar Biol Ecol 183:259-271

Ivanov BG, Sokolov VI (1997) The snow crab, Chionoecetes opilio (Crustacea, Decapoda, Brachyura, Majidae), in the Sea of Okhotsk and the Bering Sea. Arthropoda Selecta 6:63-86 (Can Transl Fish Aquat Sci 5666)

James-Pirri MJ, Cobb JS (1999) Behavioral interactions of postlarval and fifth instar lobsters (Homarus americanus) in a simulated cobble environment. Mar Freshw Behav Physiol 32:207-222

James-Pirri MJ, Cobb JS (2000) Influence of size and delayed settlement on the recapture rate of newly settled American lobsters Homarus americanus. Mar Ecol Prog Ser 208: 197-203

Jonsson A, Edsman L (1998) Moulting strategies in freshwater crayfish Pacifastacus leniusculus. Nord J Freshw Res 74: 141-147

Juanes F, Smith LD (1995) The ecological consequences of limb damage and loss in decapod crustaceans: a review and prospectus. J Exp Mar Biol Ecol 193:197-223

Kurihara Y, Okamoto K (1987) Cannibalism in a grapsid crab, Hemigrapsus pencillatus. Mar Ecol Prog Ser 41:123-127

Laval P (1975) Une analyse multivariable du développement au laboratoire de Phronima sedentaria (Forsk.), amphipode hypéride. Étude de l'influence de la température et de la quantité de nourriture. Ann Inst Océanogr 51:5-41

Lawton P (1989) Predatory interaction between the brachyuran crab Cancer pagurus and decapod crustacean prey. Mar Ecol Prog Ser 52:169-179

Lovrich GA, Ouellet P (1994) Patterns of growth and triacylglycerol content in snow crab Chionoecetes opilio 
(Brachyura: Majidae) zoeal stages reared in the laboratory. Mar Biol 120:585-591

Lovrich GA, Sainte-Marie B (1997) Cannibalism in the snow crab, Chionoecetes opilio (O. Fabricius) (Brachyura: Majidae), and its potential importance to recruitment. J Exp Mar Biol Ecol 211:225-245

Lovrich GA, Sainte-Marie B, Smith BD (1995) Depth distribution and seasonal movements of Chionoecetes opilio (Brachyura: Majidae) in Baie Sainte-Marguerite, Gulf of Saint Lawrence. Can J Zool 73:1712-1726

Luppi TA, Spivak ED, Anger K (2001) Experimental studies of predation and cannibalism of the settlers of Chasmagnathus granulata and Cyrtograpsus angulatus (Brachyura: Grapsidae). J Exp Mar Biol Ecol 265:29-48

Mattson MP, Spaziani E (1985) Stress reduces hemolymph ecdysteroid levels in the crab: mediation by the eyestalks. J Exp Zool 234:319-323

McMillan RO, Armstrong DA, Dinnel PA (1995) Comparison of intertidal habitat use and growth rates of two northern Puget Sound cohorts of 0+ age Dungeness crab, Cancer magister. Estuaries 18:390-398

Miller RJ, Watson J (1976) Growth per molt and limb regeneration in the spider crab, Chionoecetes opilio. J Fish Res Board Can 33:1644-1649

Mohamedeen H, Hartnoll RG (1989) Larval and postlarval growth of individually reared specimens of the common shore crab Carcinus maenas (L.). J Exp Mar Biol Ecol 134: $1-24$

Moksnes PO, Lipcius RN, Pihl L, Van Montfrans J (1997) Cannibal-prey dynamics in young juveniles and postlarvae of the blue crab. J Exp Mar Biol Ecol 215: $157-187$

Oh CW, Hartnoll RG (2000) Effects of food supply on the growth and survival of the common shrimp, Crangon crangon (Linnaeus, 1758) (Decapoda, Caridea). Crustaceana 73:83-99

Orth RJ, Van Montfrans J (1987) Utilization of a seagrass meadow and tidal marsh creek by blue crabs Callinectes sapidus. I. Seasonal and annual variations in abundance with emphasis on post-settlement juveniles. Mar Ecol Prog Ser 41:283-294

Pechenik JA (1990) Delayed metamorphosis by larvae of benthic marine invertebrates: does it occur? Is there a price to pay? Ophelia 32:63-94

Polis GA (1981) The evolution and dynamics of intraspecific predation. Annu Rev Ecol Syst 12:225-251

Rondeau A, Sainte-Marie B (2001) Variable mate-guarding

Editorial responsibility: Otto Kinne (Editor),

Oldendorf/Luhe, Germany time and sperm allocation by male snow crabs (Chionoecetes opilio) in response to sexual competition, and their impact on the mating success of females. Biol Bull 201: 204-217

Sainte-Marie B, Raymond S, Brêthes JC (1995) Growth and maturation of the benthic stages of male snow crab, Chionoecetes opilio (Brachyura: Majidae). Can J Fish Aquat Sci 52:903-924

Sainte-Marie B, Sévigny JM, Smith BD, Lovrich GA (1996) Recruitment variability in snow crab (Chionoecetes opilio): pattern, possible causes, and implications for fishery management. In: High latitude crabs: biology, management, and economics. Lowell Wakefield Fish Symp Ser, University of Alaska, Fairbanks, Alaska Sea Grant Coll Prog Rep 96-02, p 451-478

SAS (1999) SAS/STAT user's guide. Release 8.02. SAS Institute Press, Cary, NC

Skinner DM (1985) Molting and regeneration. In: Bliss DE, Mantel LH (eds) The biology of Crustacea. Academic Press, New York, p 44-146

Slizkin AG (1982) Distribution of snow crabs of the genus Chionoecetes and their habitat in the northern part of the Pacific Ocean. In: Population dynamics and reproductive conditions of commercial invertebrates and algae in the Far Eastern Seas, Izvestiya TINRO, Vladivostok, p 26-33 (Can Transl Fish Aquat Sci 5664)

Smith LD (1990) Patterns of limb loss in the blue crab, Callinectes sapidus Rathbun, and the effects of autotomy on growth. Bull Mar Sci 46:23-36

Snedecor GW, Cochran WG (1989) Statistical methods, 8th edn. Iowa State University Press, Ames, IA

Somerton DA (1980) A computer technique for estimating the size of sexual maturity in crabs. Can J Fish Aquat Sci 37: 1488-1494

Tarverdieva MI (1976) Feeding of the Kamchatka king crab Paralithodes camtschatica and Tanner crabs Chionoecetes bairdi and Chionoecetes opilio in the southeastern part of the Bering Sea. Sov J Mar Biol 2:34-39

Yasuda T (1967) Feeding habit of the Zuwaigani, Chionoecetes opilio elongatus, in Wakasa Bay. I. Specific composition of the stomach contents. Bull Jpn Soc Sci Fish 33: 315-319 (Fish Res Board Can Transl Ser 1111)

Zar JH (1984) Biostatistical analysis, 2nd edn. Prentice-Hall, Englewood Cliffs, NJ

Zheng J, Kruse GH (2000) Recruitment patterns of Alaskan crabs in relation to decadal shifts in climate and physical oceanography. ICES J Mar Sci 57:438-451

Submitted: April 4, 2002; Accepted: August 13, 2002

Proofs received from author(s): November 11, 2002 